\title{
BALANÇO SOCIAL E A CONTABILIDADE NO BRASIL
}

\author{
Autor: João E.P. Tinoco \\ Mestre e Doutorando em Contabilidade pela FEA/USP
}

O acesso à informação de boa qualidade é um pré-requisito para o exercício de cidadania, vale dizer, condição essencial para que os problemas sócio-econômicos sejam debatidos e resolvidos a partir do convívio democrático entre os grupos sociais.

A divulgação de informação na forma como é feita no Brasil não atende ao preceito básico de evidenciação da situação das empresas, registrando basicamente seus eventos operacionais, não captando a inserção das empresas na vida social, a forma como elas se relacionam com seus empregados, seus fornecedores, os usuários de seus serviços, o Governo etc.

A crítica a ser feita a esse tipo de postura passa pela geração de relatórios contábeis que superem as limitações ortodoxas às quais a contabilidade financeira ou tradicional se mantém presa e permitam relacionar o desempenho econômico-financeiro ao desempenho operacional, bem como explicitem a riqueza gerada pela atividade empresarial e sua distribuição entre os agentes de sua produção. À fotografia da situação patrimonial da empresa tirada pela contabilidade tradicional devem ser adicionadas imagens dinâmicas que ajudem os usuários da informação a compreender o conteúdo, extensão, significado e perspectivas apontadas pelas demonstrações contábeis. Chamemos isso de Balanço Social. ${ }^{1}$.

Um conceito modernamente aceito diz que a existência das empresas não pode se justificar exclusivamente pela capacidade que elas demonstrem de gerar lucros aos seus proprietários. Desse tipo de visão empresarial derivam programas de incentivo e motivação aos empregados, programas de treinamento, reciclagem e desenvolvimento de pessoal, políticas de benefícios sociais, atitudes de preservação e recuperação do meio ambiente, dentre outras. Pois bem, por que não evidenciar esse tipo de preocupação no balanço da empresa?. A sociedade merece ser informada desses esforços e sua divulgação é positiva para as empresas, quer do ponto de vista de sua imagem, quer do ponto de vista da melhoria e qualificação da informação contábil/financeiras.

\section{RELATÕRIO DE ADMINISTRAÇÃO}

O relatório de administração constitui-se num dos mais importantes instrumentos de evidenciação e divulgação de informação de uma entidade.

Pesquisa realizada em livros de teoria de contabilidade mostra-nos que as principais formas de evidenciação pelas entidades são:

a) Forma e Disposição dos Demonstrativos Contábeis e Formais;

b) Informação entre Parênteses;

c) Notas Explicativas;

\footnotetext{
${ }^{1}$ TINOCO. JEP e FARIAS. Adauto - Valor Adicionado e Balanço Social nas Empresas de Transportes Urbanos. publicado nos Anais do III Encontro sobre Transportes em Cidade de Porte Médio III TPM. Campina Grande /PB. de 22 a 25 de julho de 1992.
}

Caderno de Estudos nº 9 - São Paulo - FIPECAFI, Outubro/1993 
d) Quadros e Demonstrativos Suplementares;

e) Comentários do Auditor; e

f) Relatório do Conselho de Administração e/ou da Diretoria.

No que concerne à evidenciação em geral e ao relatório da administração em particular devemos mencionar que, a nosso juízo, não existe entre os pesquisadores e executivos um consenso de o que evidenciar e em que extensão fazê-lo. Três questões básicas relativas aos demonstrativos contábeis afloram ao estudar-se o que evidenciar: ${ }^{2}$

1) A quem deve ser revelada a informação?

2) Qual o propósito da informação?

3) Qual a extensão que se deve revelar?

A Comissão de Valores Mobiliários - CVM - reconhecendo a necessidade imperiosa de dotar os usuários da informação, das companhias abertas, de informação mais adequada, no seu Parecer de Orientação no 15, de 28/12/87, recomenda as seguintes divulgações em RA:

a) Descrição dos Negócios, Produtos e Serviços;

b) Comentários sobre a Cojuntura Econômica Geral;

c) Recursos Humanos;

d) Investimentos;

e) Pesquisa e Desenvolvimento;

f) Novos Produtos e Serviços;

g) Proteção ao Meio Ambiente;

h) Reformulações Administrativas;

i) Investimentos em Controladas e Coligadas:

j) Direitos dos Acionistas e Dados de Mercado:

I) Perspectivas e Planos em Curso e os Futuros;

m) Empresas Investidoras; e

n) Considerações Finais.

Recentemente, em 1990, na $3^{\mathrm{a}}$. edição do "Manual de Contabilidade das Sociedades por Ações" seus autores sugeriram a elaboração de um modelo de relatório de administração bastante evoluído para a prática brasileira contemporânea ${ }^{3}$.

O conteúdo desse. relatório apresenta uma série de proposições que vem ao encontro daquilo que se observa em alguns países desenvolvidos, especialmente na Europa. Encontramos nessa proposição informações muito valiosas, dentre outras: demonstração do valor adicionado; informações sobre recursos humanos, proteção ambiental, etc.

RELATÓRIO DE ADMINISTRAÇÃO (segundo o Manual de Contabilidade)

\section{- Análise Corporativa}

a) Estratégia Corporativa, Mudanças de Estratégia e Resultados Globais;

b) Eventos Externos incomuns que tenham afetado o desempenho do grupo e suas perspectivas;

c) Compras e/ou Vendas de Ativos significativos e seus reflexos no Resultado e na Situação Financeira;

\footnotetext{
${ }^{2}$ HENDRIKSEN. Eldon 5. - Accounting Theory. Homewood. Richard S. Irwin. 1970 (tradução espanhola de 1974. UTEHA).

${ }^{3}$ IUDíCIBUS. Sérgio de. MARTINS. Eliseu e GELBCKE. Ernesto Rubens. Manual de Contabilidade das Sociedades por Ações. $3^{\text {a }}$. edição. São Paulo. Atlas. 1990.
} 
d) Recursos Humanos, incluindo:

d.1) Informações sobre a Estrutura Organizacional e Gerencial;

d.2.) Informações sobre Assuntos de Trabalho e Emprego, incluindo Relações de Trabalho, Treinamento, Bem Estar, Segurança e Demonstração do Valor Adicionado.

e) Responsabilidade Social, com referências específicas sobre Segurança do Público Consumidor e da Comunidade e Proteção Ambiental;

f) Atividades de Pesquisa e Desenvolvimento;

g) Programa de Investimentos, incluindo a Natureza. Localização e Magnitude dos Investimentos de Capital Realizados e a Realizar;

h) Projeções Futuras da Corporação, contemplando eventos a partir do exercício encerrado apresentado.

- Análise Setorial

Deve abranger a análise de segmentos individuais, bem como as Operações Internacionais, ou então por Regiões Geográficas.

\section{- Análise Financeira}

a) Os Resultados Operacionais inclusive quanto aos efeitos dos segmentos no desempenho global e, também, a eventuais efeitos significativos ocasionados por fatores internos ou externos;

b) Situação de Liquidez e Fontes de Capital, inclusive a capacidade de atendimento de compromissos a curto e longo prazos;

c) Avaliação dos Ativos e Impacto de eventual defasagem por conta de efeitos inflacionários onde for relevante o efeito nos resultados e posição financeira;

d) Especial atenção deve ser dada aos efeitos das variações na taxa de câmbio em todos os aspectos da análise.

- Outras Informações

a) Uma descrição das atividades do empreendimento, porte e distribuição geográfica das operações;

b) Uma demonstração-resumo dos tens mais relevantes das demonstrações financeiras e estatísticas -chave para o ano;

c) Informações sobre os Diretores, incluindo Responsabilidades e Participações na Empresa;

d) Uma análise da Posição Acionária, incluindo informação dos acionistas principais.

\section{BALANÇO SOCIAL NA EMPRESA}

Nos últimos anos, especialmente na Europa, tem-se observado a elaboração de uma nova demonstração, a partir da contabilidade, que foi denominada de BALANÇO SOCIAL.

Todavia, o que vem a ser Balanço Social e a quem se dirige? O Balanço Social tem sua origem na contabilidade das empresas. Como sabemos, é normalmente através da contabilidade que as entidades divulgam aos seus diferenciados usuários o seu desempenho econômico e financeiro. No Brasil, as informações que devem ser evidenciadas foram estabelecidas pela Lei das Sociedades por Ações, Lei n ${ }^{0}$ 6.404176, especificamente em seu Artigo n 176. 
Estas informações são insuficientes já que relegam a plano secundário usuários que direta ou indiretamente contribuem na geração da riqueza de um determinado empreendimento.

Um Balanço Social é um instrumento de gestão e de informação que visa reportar, de forma mais transparente possível, informações econômicas e sociais, do desempenho das entidades, aos mais diferenciados usuários, dentre estes os trabalhadores ${ }^{4}$.

Com referência aos funcionários, as informações que mais lhes dizem respeito são: o volume dispendido pelas entidades em salários, encargos sociais e outros benefícios; informações relativas ao nível de emprego, ou seja, o número e a qualificação de funcionários trabalhando na produção e na administração, no início e no fim do exercício financeiro e, sobretudo, o valor adicionado gerado pelas entidades, bem como sua repartição, entre os vários segmentos beneficiários, que são os assalariados que recebem salários, os acionistas que auferem dividendos por lucros obtidos, os emprestadores de capitais que auferem juros por empréstimos e a própria empresa, por lucros não distribuídos ${ }^{5}$. (5)

Estas informações, que já são correntemente evidenciadas por muitas empresas nos países capitalistas, são totalmente escamoteadas na contabilidade brasileira.

Isto cabe ser feito no Balanço Social, a ser publicado conjuntamente com o Balanço Patrimonial e as outras peças contábeis e financeiras, sem que tenham até o momento causado qualquer dano ao funcionamento das instituições que assim já procederam.

Além das informações referentes a Valor Adicionado, nível de emprego e sua qualificação, bem como os salários praticados por faixa de qualificação, que muito melhoram as histórias que os Balanços contam, o Balanço social contempla, também, uma série de informações de caráter qualitativo. Dentre as mais importantes e tendo presente o exemplo da França, cuja lei sobre o Balanço Social obriga toda e qualquer entidade que possua mais de 300 trabalhadores a publicálo, destacam-se: informações relativas à ecologia, onde se evidenciam os esforços que as empresas vem realizando para não afetar a fauna, a flora e a vida humanas, vale dizer as relações da entidade com o meio ambiente; informações concernentes à formação profissional dos trabalhadores; condições de higiene e segurança no trabalho, onde se descreve as condições em que se desenvolve o trabalho, tudo em conformidade com as posturas legais; outras informações indicadoras das condições de vida dos trabalhadores, como alojamento, transporte entre residência e trabalho, relações profissionais e outras condições de vida dependentes das entidades ${ }^{6}$.

Dentre outras questões importantes realçam-se os tributos que são recolhidos pelas empresas ao fisco. O valor adicionado (Demonstrativo) ao evidenciar como é repartida a riqueza gerada por uma entidade mostra claramente, quanto dessa riqueza o fisco está se apropriando. Sabe-se, que atualmente no Brasil a carga tributária imposta às empresas é de grande monta. Uma observação atenta desse demonstrativo explicita qual a grandeza dos tributos, em relação ao Valor Adicionado, bem como sua evolução ao longo dos anos.

Urge, mudar já a Lei das S/A, introduzindo nesta a demonstração do Valor Adicionado; informações sobre emprego e salários; informações sobre ecologia e meio ambiente e outras informações atinentes à vida das empresas.

\footnotetext{
${ }^{4}$ TINOCO, João E.P. - Balanço Social - Uma abordagem Sócio-Econômico da Contabilidade, Dissertação de Mestrado. Departamento de Contabilidade e Atuária da FEAIUSP, 1984.

${ }^{5}$ TINOCO, João E. P., op. citado.

${ }^{6}$ Lei $n^{0} 77.769$ du 12 juillet 1977 relative au bilan social de l'entreprise (lei francesa também conhecida como "rapport" Sudreau).
} 